\title{
Glycerol as a partial replacement for lactose in milk replacer for young dairy calves
}

\author{
R. A. Ebert-Allen, ${ }^{1 *}$ G. M. Willis, ${ }^{2} \dagger$ and J. K. Drackley ${ }^{1} \neq \odot$
}

\section{Graphical Abstract}

Treatments were milk replacers

Control: All milk protein, $28 \% \mathrm{CP}, 15 \%$ fat, $46 \%$ lactose

\section{Results:}

Glycerol: $15 \%$ replacing lactose in controls

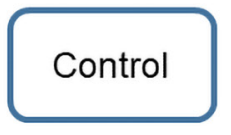

12 calves

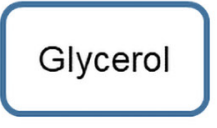

12 calves

Calves fed milk replacers from $\mathrm{d} 2$ to $d 49$, measured through d 56

- No differences in body weight, stature measurements, or gain:feed

- No health issues

\section{Conclusion:}

Glycerol can replace $15 \%$ of the lactose in an all-milk milk replacer without loss of performance or health

\section{Summary}

Two groups of 12 calves were used to determine whether glycerol could be included at $15 \%$ of the milk replacer formula replacing lactose. Liquid glycerol was added to a base milk replacer at each feeding. Calves were fed the diets from $\mathrm{d} 3$ of age to $\mathrm{d} 49$. There were no differences between treatments in body weight, stature measurements, gain:feed, or health issues. Glycerol can replace $37.5 \%$ of the lactose (15\% of the formula) in milk replacer with no loss of performance.

\section{Highlights}

- Liquid glycerol was added to a base milk replacer at each feeding.

- Glycerol replaced lactose ( $15 \%$ of the formula, replaced $37.5 \%$ of the lactose).

- Calves were fed diets from d 3 through 49.

- No differences were detected between diets for growth, feed efficiency, or health.

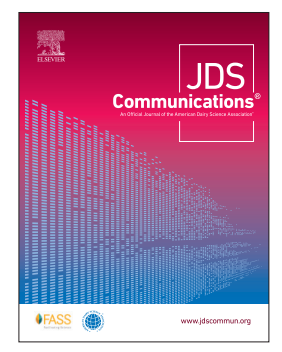




\title{
Glycerol as a partial replacement for lactose in milk replacer for young dairy calves
}

\author{
R. A. Ebert-Allen, ${ }^{1 *}$ G. M. Willis, ${ }^{2} \dagger$ and J. K. Drackley ${ }^{1} \ddagger \odot$
}

\begin{abstract}
Glycerol (glycerin) is increasingly available from biodiesel manufacture and edible oil refining and it has been used successfully in diets for chickens, pigs, and adult cattle; however, less information is available on its nutritional value in young calves. Our objective was to determine the effects on calf growth and health when glycerol replaced a portion of lactose in milk replacer. Holstein calves (12 male, 12 female) born at the University of Illinois dairy unit were assigned alternately to 1 of 2 treatments ( 24 calves total): control milk replacer or milk replacer supplemented with $15 \%$ glycerol in replacement of lactose. The experimental base milk replacer contained greater protein, fat, minerals, and vitamins so that when glycerol was added, the composition would be the same as that of the control, except that glycerol replaced some lactose. Calves were housed in individual hutches bedded with straw, and water was freely available. Starter was offered beginning on $\mathrm{d} 36$. The amount of milk replacer offered was reduced by half on $\mathrm{d} 43$, and calves were weaned at $\mathrm{d} 49$. Calves were fed milk replacers twice daily from d 3 of life. Milk replacers contained $28 \%$ protein (all from whey proteins), $2.6 \%$ lysine, and $15 \%$ fat. Control milk replacer contained $40 \%$ lactose, and the glycerol milk replacer contained $25 \%$ lactose. Both replacers were reconstituted to $15 \%$ solids. Glycerol (liquid) was added to reconstituted base milk replacer at each feeding. During wk 1, milk replacers were fed at a rate of $0.25 \mathrm{Mcal} / \mathrm{kg}$ of metabolic body weight (BW) (about $1.5 \%$ of BW daily as powder, or approximately $675 \mathrm{~g} / \mathrm{d}$ ) and from wk 2 to 6 at $0.30 \mathrm{Mcal} / \mathrm{kg}$ of metabolic BW (about 2\% of BW daily, or approximately 900 to $1,200 \mathrm{~g} / \mathrm{d}$ ). Measurements of BW and stature were made weekly through d 56. Calf BW and average daily gain through d $35(0.66 \mathrm{vs.} 0.65 \mathrm{~kg} / \mathrm{d}$ for controls and glycerol, respectively) did not differ significantly between treatments. Stature measurements (withers height, body length, heart girth) and measures of health (fecal scores, medical treatments) did not differ between treatments. Under the conditions of this experiment, glycerol was an acceptable replacement for at least $37.5 \%$ of the total lactose in milk replacer ( $15 \%$ of the formula) if economically favorable.
\end{abstract}

actose is the primary ingredient in milk replacers for young -calves, constituting 40 to $50 \%$ of the DM in the formula. The high and variable cost of dairy ingredients creates an economic incentive to replace ingredients such as lactose with nondairy energy sources. One possible ingredient is glycerol, which is widely available from biodiesel manufacture and edible oil refining. Glycerol is rapidly absorbed from the small intestine (Höber and Höber, 1937) by passive diffusion and by $\mathrm{Na}^{+}$-dependent carriers (Kato et al., 2005). Glycerol can be directly oxidized or converted into glucose by the liver in the process of gluconeogenesis. Glycerol has been successfully used in feeding poultry (Lima et al., 2013), swine (Hernández et al., 2016), and adult cattle (Kholif, 2019). However, less is known about its potential use in milk replacer for young dairy calves.

Our hypothesis was that growth would be less when calves were fed a milk replacer containing $15 \%$ glycerol. Our objective was to determine whether glycerol could replace a portion of the lactose in an "all-milk" milk replacer formula without compromising growth and health of young calves.

All procedures were approved by the University of Illinois Institutional Animal Care and Use Committee (IACUC protocol number 06132). Holstein calves (24 in total; 6 male and 6 female calves per treatment) born at the University of Illinois dairy unit from May through June 2007 were housed in individual hutches bedded with straw; water was freely available at all times. The number of calves chosen was sufficient to detect a $0.15 \mathrm{~kg} / \mathrm{d}$ dif- ference in ADG between treatments at the $P=0.05$ level with $80 \%$ power. Calves were managed at birth and for the first $2 \mathrm{~d}$ according to standard protocols at the dairy unit. Calves received a minimum of $3 \mathrm{~L}$ of colostrum as soon as possible after birth and were then fed colostrum and transition milk (2 L per feeding) through d 2 of life.

Calves were assigned alternately to each of 2 milk replacer treatments ( 24 calves total) beginning on d 3 of life. Treatments were an all-milk protein-based milk replacer (Excelerate, Milk Specialties Global) containing 28\% CP, 2.6\% lysine, and 15\% fat, with all carbohydrate as lactose; or an all-milk protein-based milk replacer with similar $\mathrm{CP}$, lysine, and fat contents as the control but supplemented with 15\% glycerol (Sigma Chemical Co.) replacing a portion of the lactose. The base milk replacer for the glycerol diet (Table 1) contained greater amounts of protein, fat, minerals, and vitamins than the control diet so that when glycerol was added, the final composition would be the same as that of the control, except that glycerol replaced $37.5 \%$ of the lactose. The control milk replacer contained $40 \%$ lactose; the glycerol milk replacer, as fed, contained $25 \%$ lactose. The substitution of glycerol for lactose would be expected to increase the osmolality of a $15 \%$ reconstituted milk replacer solution by $179 \mathrm{mOsm} / \mathrm{kg}$. Diets were formulated to meet or exceed established requirements for all other nutrients (NRC, 2001). Both milk replacers were reconstituted to $15 \%$ solids and fed twice daily. Glycerol (liquid) was added to reconstituted base milk replacer at each feeding.

\footnotetext{
${ }^{1}$ Department of Animal Sciences, University of Illinois Urbana-Champaign, Urbana 61801, ${ }^{2}$ Milk Specialties Global, Eden Prairie, MN 55344. *Present address: Jump Simulation, 1306 N. Berkeley Ave., Peoria, IL 61603. tPresent address: 1463 Valley Dr., Robertsville, MO 63072. ‡Corresponding author: drackley@ illinois.edu. $\odot$ 2022, The Authors. Published by Elsevier Inc. and Fass Inc. on behalf of the American Dairy Science Association ${ }^{\oplus}$. This is an open access article under the CC BY license (http://creativecommons.org/licenses/by/4.0/). Received October 25, 2021. Accepted December 14, 2021.
} 
Table 1. Formulated composition of milk replacers (\% as received unless otherwise noted)

\begin{tabular}{lcc}
\hline & \multicolumn{2}{c}{ Diet } \\
\cline { 2 - 3 } Component & Control & Glycerol \\
\hline CP & 28.5 & 33.5 \\
Crude fat & 15.0 & 17.6 \\
Ash & 7.0 & 6.7 \\
Lactose & 40.1 & 32.9 \\
Gross energy $(\mathrm{kcal} / \mathrm{kg})$ & 4,635 & 4,882 \\
Calcium & 0.90 & 0.98 \\
Phosphorus & 0.67 & 0.67 \\
Lysine & 2.79 & 3.31 \\
Methionine & 0.58 & 0.68 \\
Cysteine & 0.87 & 1.05 \\
Histidine & 0.46 & 0.54 \\
Isoleucine & 1.76 & 2.07 \\
Leucine & 2.98 & 3.52 \\
Valine & 1.66 & 1.97 \\
Arginine & 0.76 & 0.88 \\
Phenylalanine & 0.92 & 1.09 \\
Tyrosine & 0.82 & 0.97 \\
Threonine & 1.95 & 2.32 \\
Tryptophan & 0.44 & 0.51 \\
\hline
\end{tabular}

Milk replacers were fed at a rate of $0.25 \mathrm{Mcal}$ of gross energy/ $\mathrm{kg}$ of $\mathrm{BW}^{0.75}$ (where $\mathrm{BW}^{0.75}$ represents metabolic $\mathrm{BW}$ ) during wk 1 , and at a rate of $0.30 \mathrm{Mcal} / \mathrm{kg}$ of $\mathrm{BW}^{0.75}$ from wk 2 through 6 . These feeding rates equated to approximately $1.5 \%$ and $2 \%$ of BW (as powder) daily, respectively. Amounts fed were adjusted weekly as calves grew. No starter feed was offered until the beginning of wk 6 to avoid the variability introduced by dry feed consumption. During wk 6 to 8, starter (18\% CP, 14\% NDF) was offered for ad libitum intake to all calves. At the start of wk 7, the amount of milk replacer was increased according to that week's BW and then the amount fed was reduced by half (i.e., the afternoon feeding was eliminated). Calves were weaned at the end of wk 7 and remained in the hutches through wk 8. Measurements and feed amount adjustments were made on the same day each week. The calf's actual age at each experimental week was recorded and used as a covariate in statistical analysis where appropriate.

Intakes of milk replacer and starter were recorded daily. Feeds were sampled weekly and then formed into monthly composites.
Measurements of BW, withers height, body length, and heart girth were made weekly through $\mathrm{d} 56$. All health data (daily scour scores, respiratory scores, and medical treatments) were recorded. Fecal scores were assigned on a $1=$ firm to $4=$ watery diarrhea scale. Respiratory scores were assigned based on the scale developed by the University of Wisconsin (https:/www.vetmed.wisc .edu/fapm/svm-dairy-apps/calf-health-scorer-chs/). At completion of the study, female calves remained in the herd and male calves were sold.

Data were analyzed statistically using the Mixed procedure of SAS (v. 9.1; SAS Institute Inc.). Separate statistical analyses were conducted for the period from birth through wk 5 (when only milk replacer was fed), from wk 6 through 8 (when starter was fed), and from birth through the end of the trial at wk 8 . Variables measured at the end of wk 5 (total milk replacer intake, BW, ADG, stature measurements, and gain:feed) and wk 8 (starter intake, total DMI, BW, ADG, gain:feed, stature measurements) were analyzed using an initial model that contained birth BW and age at measurement as continuous variables (covariates), diet, sex, and diet $\times$ sex. Effects of birth BW, age, sex, and diet $\times$ sex were not retained in the final model if $P>0.15$. Weekly growth measurements were analyzed as repeated measures with an initial model that contained the effects of birth BW as a continuous variable (covariate), diet, sex, diet $\times$ sex, week, diet $\times$ week, sex $\times$ week, and diet $\times \operatorname{sex} \times$ week. Calf was the experimental unit, and the effects of week and its interactions were tested with the model residual error. Several covariance structures were examined, and the one that yielded the lowest Akaike's information criterion (first-order autoregressive with heterogeneous variance) was used in the model. Health data were evaluated by logistic regression using a binomial distribution in the GLIMMIX procedure in SAS. Least squares means were calculated and are presented throughout. Because animal numbers were limited, results were considered statistically significant when $P<0.10$.

Diets mixed easily and were stable in solution. Calves readily consumed both diets with no apparent palatability or acceptability problems. Mean fecal scores (Table 2) did not differ during the milk replacer feeding period (mean 2.7 on a 5-point scale) or for the entire trial (mean 2.6). Incidences of other health events are tabulated in Table 2. Of note is the greater incidence of navel infections for calves fed the glycerol-supplemented milk replacer. In all

Table 2. Health data for calves ( $n=12$ per diet) fed only a control milk replacer or a similar milk replacer with glycerol replacing a portion of the lactose during wk 1 to 5 , with starter offered during wk 6 to 8

\begin{tabular}{|c|c|c|c|c|}
\hline \multirow[b]{2}{*}{ Item } & \multicolumn{2}{|c|}{ Diet } & \multirow[b]{2}{*}{ SEM } & \multirow[b]{2}{*}{$P<$} \\
\hline & Control & Glycerol & & \\
\hline \multicolumn{5}{|l|}{ Average fecal score $^{1}$} \\
\hline Wk 1 to 5 & 2.72 & 2.73 & 0.037 & 0.75 \\
\hline Wk 1 to 8 & 2.62 & 2.58 & 0.047 & 0.54 \\
\hline \multicolumn{5}{|c|}{ Average days with fecal score $>3^{1}$} \\
\hline Wk 1 to 5 & 1.33 & 1.75 & 0.53 & 0.59 \\
\hline Wk 1 to 8 & 1.58 & 1.75 & 0.58 & 0.84 \\
\hline Respiratory disease ${ }^{2}$ & 1 & 1 & - & - \\
\hline Navel infection ${ }^{2}$ & 2 & 8 & - & - \\
\hline Ear infection ${ }^{2}$ & 0 & 1 & - & - \\
\hline Horn infection ${ }^{2}$ & 1 & 0 & - & - \\
\hline
\end{tabular}


Table 3. Growth measurements for calves ( $n=12$ per diet) fed a control milk replacer or a similar milk replacer with glycerol replacing a portion of the lactose

\begin{tabular}{lcccc}
\hline & \multicolumn{2}{c}{ Diet } & & \\
\cline { 2 - 3 } Variable & Control & Glycerol & SEM & P-value \\
\hline Birth BW' ${ }^{1}(\mathrm{~kg})$ & 43.3 & 43.6 & 1.79 & 0.93 \\
Actual age at wk 5 (d) & 35.5 & 34.4 & 0.57 & 0.19 \\
BW, wk 5 (kg) & 66.8 & 66.4 & 0.96 & 0.78 \\
ADG, wk 1 to 5 (kg) & 0.66 & 0.65 & 0.028 & 0.77 \\
Milk replacer intake, wk 1 to 5 (kg/d) & 1.03 & 1.02 & 0.026 & 0.67 \\
Gain:feed, wk 1 to 5 & 0.64 & 0.64 & 0.015 & 0.75 \\
Withers height, ${ }^{3}$ wk 5 (cm) & 85.3 & 86.2 & 0.66 & 0.39 \\
Heart girth, wk 5 (cm) & 90.8 & 90.8 & 0.62 & 0.95 \\
Body length, wk 5 (cm) & 69.5 & 69.0 & 0.47 & 0.49 \\
Actual age at wk 8 (d) & 56.5 & 55.4 & 0.57 & 0.19 \\
BW, wk 8 (kg) & 76.0 & 75.0 & 1.82 & 0.71 \\
ADG, wk 6 to 8 $(\mathrm{kg})$ & 0.50 & 0.46 & 0.031 & 0.34 \\
ADG, wk 1 to 8 $(\mathrm{kg})$ & 0.58 & 0.56 & 0.032 & 0.71 \\
Starter intake, wk 6 to 8 (kg/d) & 0.88 & 0.82 & 0.072 & 0.52 \\
Total DMl, wk 1 to 8 (kg/d) & 0.98 & 0.94 & 0.040 & 0.55 \\
Gain:feed, wk 1 to 8 & 0.62 & 0.62 & 0.013 & 0.97 \\
Withers height, ${ }^{5}$ wk 8 (cm) & 89.2 & 89.2 & 0.76 & 0.99 \\
Heart girth, wk 8 (cm) & 95.9 & 95.0 & 1.04 & 0.54 \\
Body length, ${ }^{6}$ wk 8 (cm) & 74.2 & 73.9 & 0.60 & 0.77 \\
\hline
\end{tabular}

${ }^{1}$ Sex effect, $P=0.16($ male $=45.3 \mathrm{~kg}$, female $=41.6 \mathrm{~kg})$.

${ }^{2}$ Diet by sex interaction, $P<0.05$ (male control $=0.63$, male glycerol $=0.68$, female control $=0.66$, female glycerol $=0.60$ ).

${ }^{3}$ Sex effect, $P<0.03$ (male $=84.6 \mathrm{~cm}$, female $=86.9 \mathrm{~cm}$ ).

${ }^{4}$ Diet by sex interaction, $P<0.05$ (male control $=0.63$, male glycerol $=0.67$, female control $=0.61$, female glycerol $=0.57$ ).

${ }^{5}$ Sex effect, $P=0.15$ (male $=88.4 \mathrm{~cm}$, female $\left.=90.1 \mathrm{~cm}\right)$.

${ }^{6}$ Sex effect, $P=0.07$ (male $=73.2 \mathrm{~cm}$, female $=74.9 \mathrm{~cm}$ ).

but one calf, the first diagnosis of navel infection was made within $3 \mathrm{~d}$ after birth, when the experimental treatments began. For the other calf, the navel infection occurred subsequent to respiratory illness and heat stress. Consequently, it is highly unlikely that the greater number of navel infections was related to the glycerol supplementation. Nevertheless, the high incidence of navel infections could have increased maintenance needs for energy and protein, thus decreasing growth in the affected calves.

Birth BW and age at measurement did not differ between treatment groups (Table 3). The final model-adjusted BW and ADG at wk 5 did not differ between diets (Table 3). Milk replacer intake, gain:feed, withers height, heart girth, and body length also did not differ between diets. The interaction of sex $\times$ diet was significant for gain:feed ratio (Table 3), with bulls having greater efficiency when fed the glycerol diet but heifers having greater efficiency when fed the control diet. An explanation for this result is not readily evident but it might be an artifact of the relatively small data set.

Over the first $5 \mathrm{wk}$ when only milk replacers were fed, repeatedmeasures analysis revealed a tendency $(P=0.13)$ for an interaction of diet $\times$ week for BW (not shown). Visual inspection of this interaction indicated that calves fed the control diet tended to have slightly greater rates of BW increase through wk 3, with parallel growth after that. These tendencies for BW were not reflected in patterns of change for withers height, body length, or heart girth (not shown). When the entire $8 \mathrm{wk}$ of data were analyzed, differences between treatments for all variables did not approach significance (Table 3 ). The interaction of sex $\times$ diet again was significant for gain:feed (Table 3), with bulls having greater efficiency when fed the glycerol diet but heifers having greater efficiency when fed the control diet. Repeated-measures analysis of weekly measurements largely reflected the effects of the first $5 \mathrm{wk}$.

The similar growth between diets agrees with others who have fed glycerol to young calves. Vermeire (2008) found that calves fed a milk replacer with $10 \%$ glycerol addition replacing lactose grew similarly to those fed a milk replacer containing all lactose. Gilbert et al. (2016) replaced $15 \%$ of the lactose in a milk replacer and reported that calf growth, energy partitioning, and $\mathrm{N}$ retention were not different from calves fed an all-lactose milk replacer.

It must be noted that the glycerol fed in this experiment was of high purity and did not contain methanol; results for calves fed crude glycerol from biodiesel manufacture might be different. Glycerol is currently available and usable only in liquid form for calves and will not spray-dry into milk replacer powders. Consequently, at present, glycerol would only have utility in feeds prepared and delivered in liquid form.

In conclusion, glycerol was well tolerated by calves and resulted in growth and health that were similar to that of calves fed the control all-lactose formula. These results indicate that calves could be fed at least $15 \%$ glycerol in replacement for $37.5 \%$ of the lactose in milk replacer without detriment if economics were favorable.

\section{References}

Gilbert, M. S., A. J. Pantophlet, J. J. G. C. van den Borne, W. H. Hendriks, H. A. Schols, and W. J. J. Gerrits. 2016. Effects of replacing lactose from milk replacer by glucose, fructose, or glycerol on energy partitioning in veal calves. J. Dairy Sci. 99:1121-1132. https://doi.org/10.3168/jds.2015 -10062 .

Hernández, F., J. Orengo, C. Villodre, S. Martínez, M. J. López, and J. Madrid. 2016. Addition of crude glycerin to pig diets: Sow and litter performance, 
and metabolic and feed intake regulating hormones. Animal 10:919-926. https://doi.org/10.1017/S175173111500275X.

Höber, R., and J. Höber. 1937. Experiments on the absorption of organic solutes in the small intestine of rats. J. Cell. Comp. Physiol. 10:401-422. https:// doi.org/10.1002/jcp.1030100402.

Kato, T., Y. Hayashi, K. Inoue, and H. Yuasa. 2005. Glycerol absorption by $\mathrm{Na}^{+}$-dependent carrier-mediated transport in the closed loop of the rat small intestine. Biol. Pharm. Bull. 28:553-555. https://doi.org/10.1248/bpb.28 .553 .

Kholif, A. E. 2019. Glycerol use in dairy diets: A systemic review. Anim. Nutr. 5:209-216. https://doi.org/10.1016/j.aninu.2019.06.002.

Lima, E. M. C., P. B. Rodrigues, R. R. Alvarenga, V. M. P. Bernardino, L. Makiyama, R. R. Lima, V. S. Cantarelli, and M. G. Zangeronimo. 2013. The energy value of biodiesel glycerine products fed to broilers at different ages. J. Anim. Physiol. Anim. Nutr. (Berl.) 97:896-903.
NRC. 2001. Nutrient Requirements of Dairy Cattle. 7th rev. ed. Natl. Acad. Press.

Vermeire, D. A. 2008. Milk replacer composition and product and method for producing the same. US Patent 20080260895A1.

\section{Notes}

J. K. Drackley (1) https://orcid.org/0000-0002-4560-5594

Funding for this study was provided by Milk Specialties Global (Eden Prairie, $\mathrm{MN})$.

The authors have not stated any conflicts of interest. 